\title{
POR UMA DESGLOBALIZAÇÃO DA PRODUÇÃO ALIMENTAR - COMMODITIZAÇÃO DA AGRICULTURA E DIVERSIDADE PRODUTIVA: UMA ANÁLISE DE ESPANHA
}

\section{JOSÉ GILBERTO DE SOUZA ${ }^{1}$}

\author{
UNESP - Rio Claro
}

\section{VALENTIN CABERO DIEGUES ${ }^{2}$}

Universidade de Salamanca

\section{Introdução}

O presente trabalho tem por objetivo apresentar uma reflexão sobre os ainda positivos efeitos da Política Agrícola Comum da União Europeia (PAC-EU) no que diz respeito à sua diversidade produtiva, particularmente em Espanha. A análise realiza-se sobre as formas de uso e ocupação do solo. No período de 2002 a 2010, nas 17 Comunidades Autônomas, e aponta para uma reflexão sobre a necessidade de "desglobalizar" a produção e o consumo de alimentos como estratégia de preservação ambiental e sócio-produtiva, como forma de reprodução social do campesinato, da manutenção do banco genético de alimentos, considerando o processo de privatização ("patenteamento") da vida, sementes e dos princípios ativos naturais realizados com o avanço do capital monopolista sobre o campo brasileiro (Souza, 2010).

A produção campesina sofre ataques contundentes em todos os países do mundo. As suas lógicas de produção e relação com a terra, quando se sustentam na consolidação de instrumentos distantes do

${ }^{1}$ Professor Adjunto do Departamento de Geografia do Instituto de Geociências e Ciências Exatas (IGCE) Unesp. Campos de Rio Claro.São Paulo. Brasil jgilbert@rc.unesp.br

${ }^{2}$ Decano da Facultad de Geografía e Historia da Universidade de Salamanca (Salamanca - Espanha) vcd@usal.es 
mercado, criam territórios de resistência e elaboram representações territoriais que são enfrentamentos diretos ao modelo de concentração do capitalismo contemporâneo, em sua fase mais aguda de monopolização, mas que são pressionados pela lógica mercantil nos processos de commoditização da agricultura (Souza, 2009).

A criação dos territórios camponeses estabelece-se pelas relações sociais de produção solidárias e de âmbito familiar, em oposição aos processos de subsunção do trabalho no campo pela diversidade da matriz produtiva. Configura-se, portanto, como antítese à lógica de commoditização da produção agrícola, sobretudo alimentar, integrando trabalho, produção e cultura regional pela diversidade produtiva como capacidade de preservação de banco genético e em oposição à artificialização e à mercantilização da natureza, vis a vis, as sementes transgênicas, os circuitos oligopsônicos e oligopólicos de comercialização dos produtos e de determinação de pacotes tecnológicos, que comprometem sobejamente a sustentabilidade dos ecossistemas em que estão inseridos.

Assim, em âmbito mundial, torna-se necessário desfazer, em parte, o discurso de oposição às políticas de apoio ao desenvolvimento rural, como o projeto LEADER (Esparcia Pérez, Noguera Tur, Pitarch Garrido, 2000) e de produção agrícolas realizadas pela Política Agrícola Comum Européia (PAC-UE), considerando ser esse discurso portador de um anúncio futuro de destruição da diversidade produtiva e de aprofundamento das relações de dependência dos países periféricos, via "primarização" de suas economias, deterioração dos termos de troca e consolidação dos modelos de divisão internacional do trabalho.

O discurso de oposição às políticas de apoio à produção agrícola europeia coloca-se em uma perspectiva economicista dos custos de produção, de liberalização comercial e de padronização do consumo alimentar, que representam ampliação das taxas de lucros dos setores que oligopolizam a produção e a comercialização de alimentos e, por sua vez, no caso europeu, verifica-se um quadro de despovoamento do campo, de abandono de áreas de produção e, sobretudo, da redução da diversidade produtiva e, consequentemente, provocam desastres ambientais, como incêndios e desertificação. (España, 2008).

Um processo com rebatimentos claros nos países produtores de commodities agropecuárias, considerando que tais alterações, na agricultura europeia, que já vêm em curso, produzem pressões na demanda 
de alimentos, bem como de agrocombustíveis, determinando alterações nos preços de terras, a incorporação dos territórios campesinos aos sistemas agroindustriais exportadores, aprofundando os processos hegemônicos do capital monopolista no campo e ampliando os processos de homogeneização da paisagem e dos sistemas de produção (Souza, 2008).

Nos últimos anos, a agricultura europeia tem sofrido inúmeras transformações demográficas, ambientais e produtivas. Tais transformações têm concorrido com dinâmicas de concentração da terra e de padronização dos sistemas de produção, concomitante a uma trajetória de envelhecimento da população rural e o abandono das áreas de produção.

Da mesma forma, as políticas agrícolas passaram a apresentar características seletivas em relação ao perfil produtivo e sócio-econômico dos produtores rurais e sua distribuição geográfica. Essas lógicas seletivas vêm paulatinamente provocando a exclusão de agricultores campesinos, sobretudo aqueles com menores parcelas de terras e que vivem em áreas de proteção ambiental (montanhas) e com produção não essencialmente comercial. (Cabero Diegues, 2006).

No caso da Espanha, esse processo não se difere, sobretudo em período de crise vivenciada na Europa em que a condição de reprodução dos campesinos se revela com inúmeras dificuldades e a pobreza no campo acentua-se. (Cabero Diegues, Trejo Jiménez e Fernández Fernández, 2010).

Não obstante, mesmo no enfrentamento desta conjuntura, a agricultura espanhola apresenta um caráter diferenciador: em que pese as transformações no campo e as alterações promovidas na Política Agrícola Comum, esses mecanismos seletivos e tendencialmente excludentes ainda representam formas de manutenção de uma agricultura e produzem efeitos sobre a diversidade produtiva no uso e na ocupação do solo e de capacidade de resistência aos produtores campesinos, o que implica uma perspectiva mais crítica ao uníssono discurso de abertura comercial e fim das políticas públicas no campo europeu.

As formas de uso e ocupação do solo em Espanha passaram por profundas transformações nos últimos 30 anos. Elas foram conduzidas por processos de modernização e especialização produtiva, que constituíram agrossistemas interferentes nos elementos determinantes de composição do território, quais sejam os homens (campesinos), as formas de trabalho, os capitais de produção, as matrizes produtivas e as formas de equilíbrio dos fatores terra e água, e, sobretudo, das paisagens naturais. Essas 
transformações territoriais compuseram paisagens agrárias modernas e tradicionais, sendo que essas últimas, paulatinamente, perdem dimensões espaciais, em que pese sua riqueza cultural e patrimonial. (Mata Olmo, 2009).

Dessa forma, a composição paisagística de Espanha resulta em grande diversidade, desde um ponto de vista mais específico dos domínios naturais preservados, bem como de suas estruturas agrárias. No entanto, tal composição é profundamente marcada por fatores como o regime e o balanço hídrico e o volume de calor, considerando assim seus impactos em termos de escala na península e nos arquipélagos.

Assim, três grandes ambientes agroecológicos são constituídos: i) atlântico úmido, ii) mediterrâneo seco e iii) semiárido. Destaca Mata Olmo (2009) que o primeiro ambiente é de domínio das pradarias naturais, do "matorral higrófilo e do bosque caducifólio". O segundo ambiente, o do mediterrâneo seco, é de predomínio dos cultivos tradicionais, denominados de "secano", compostos de vegetações "herbaceas e lenhosas". Essa formação tem como contraponto as áreas irrigadas com pastagens e "encinas", sobretudo nas áreas de solos rasos. O terceiro ambiente ocupa as áreas do noroeste peninsular, certos enclaves na bacia do Rio Duero e do Ebro, de La Mancha e as Ilhas Canárias.

Por sua vez, todos estes elementos naturais - umidade, insolação, o relevo e solos -, juntamente com a estrutura agrária, são importantes nas formas de distribuição espacial dos cultivos.

Desta forma, esse conjunto de elementos acaba consolidando tipos de agrossistemas, tais como os cultivos "herbáceos de secano", os cultivos de "regadío", as explorações de "montañas", os cultivos lenhosos mediterrâneos - basicamente os "olivares e viñedos" -, as terras "adehesadas" do oeste peninsular; os policultivos e pradarias do atlântico úmido.

Esses são grandes sistemas que variam suas escalas e graus de heterogeneidade $\mathrm{e}$ homogeneidade segundo às estruturas fundiárias, ao perfil de densidade de ocupação humana, caracterizada aqui como o nível de abandono do território, conceito este que se associa ao efetivo abandono das práticas agrícolas. (Di Pietro \& Balent, 1997; Nunes, 2008). 


\section{Ocupação e uso do solo em Espanha}

Neste trabalho, as análises concentram-se nos "labradíos herbáceos de secano", considerando sua importância em área e número de unidades agrícolas envolvidas no processo produtivo, bem como no volume de recursos destinados à produção nestas áreas e sua tendência de homogeneização e padronização produtiva.

Como salientamos, a ocupação e o uso do solo caracterizam-se como a centralidade de análise, uma vez que é um mecanismo capaz de expressar as profundas variações vivenciadas pelo meio rural. Em verdade, os cultivos, suas espacializações e sistemas de produção são elementos que permitem inferir sobre as lógicas de determinação territorial, considerando que expressam as tendências da estrutura fundiária; de organização do trabalho; da permanência de modos de vida e, por sua vez, de patrimônios tangíveis e intangíveis; dinâmicas de mercados de terras e produtos agrícolas e, sobretudo, da sustentabilidade dessas mudanças. Um processo que implica relações sociais de produção e, imediatamente, relações sociais de poder.

O território é sem sombra de dúvidas a primeira maneira de dar significado às relações de poder, ou seja, o território é um primeiro campo, no seio do qual, o poder se articula. Ele não é o único campo, por isso a importância das análises sobre as territorialidades, mas se constitui em um meio persistente e recorrente de dar eficácia à significação do poder e deve ser compreendido por meio de outras categorias de análise, como classe, sistemas de produção, tecnologia, trabalho, identidade, representação, objetivação, intencionalidade e até mesmo estrutura. (Souza, 2009:107).

\subsection{Os "labradíos herbáceos de secano"}

Esta formação paisagística ("labradíos herbáceos de secano") domina as áreas de produção agrícola em Espanha e, em 2010, respondia por 80\% de todas as formas de uso e ocupação do solo no país, o que significa uma área de aproximadamente 14 milhões de hectares.

Ainda que se considere a importância das culturas de regadios (irrigações) do ponto de vista da manutenção da atividade produtiva em determinadas regiões frente aos períodos de estiagem, nesta análise, será 
considerada apenas essa forma de agricultura frente, ainda, sua capacidade de incluir os cultivos de agricultores menos capitalizados do país

Desta forma, apresentam-se as principais culturas herbáceas e suas trajetórias de desenvolvimento no período de 2002 a 2010 e como essas articulam-se às características geomorfológicas, climáticas e sócioprodutivas que foram sendo consolidadas ao longo de séculos e que atualmente passam por profundas mudanças.

O principal e maior grupo de culturas em área dessa formação paisagística concentra-se na produção de grãos. Observa-se na tabela 1 que a produção de grãos ocupa faixa superior a cinco milhões de hectares e representa, em termos agrícolas, o principal grupo de área do país.

Em termos relativos, esses cultivos ocupam em média 11,3\% do total da área vinculada à exploração agrícola e pecuária. Em termos absolutos, a produção apresenta, a partir de 2008, uma queda constante em área, respondendo por esse fato a inflexão negativa nas culturas de trigo (duro e blando), cevada e outros cereais, esse último, oscilando inflexões negativas e positivas.

Tabela 1. Grãos Cultivados (ha) Espanha 2002-2010.

\begin{tabular}{lrrrrr}
\hline & \multicolumn{5}{c}{ Período } \\
\cline { 2 - 6 } Culturas & \multicolumn{1}{c}{2002} & \multicolumn{1}{c}{2004} & \multicolumn{1}{c}{2006} & \multicolumn{1}{c}{2008} & \multicolumn{1}{c}{2010} \\
\hline Trigo dur & 925.542 & 911.662 & 710.401 & 620.413 & 544.496 \\
Trigo blan. & 1.318 .027 & 1.098 .906 & 1.148 .554 & 1.344 .079 & 1.278 .126 \\
Cebada & 3.068 .507 & 3.056 .029 & 3.137 .358 & 3.406 .239 & 2.795 .900 \\
Avena & 399.944 & 381.132 & 439.731 & 457.998 & 404.125 \\
O.cereales & 207.429 & 204.467 & 236.672 & 205.937 & 233.827 \\
\hline Totales & 5.921 .450 & 5.654 .200 & 5.674 .722 & 6.036 .674 & 5.258 .484
\end{tabular}

Fonte : Ministério da Agricultura, Pesca e Alimentacão (Espanha) 2010.

Esse grupo, do ponto de vista da participação das explorações por faixa de tamanho, indica claramente uma tendência de concentração das atividades agrárias e de especialização regional produtiva, em decorrência da lógica de custos e da escala de produção.

Em 2003, o número de unidades de produção atingia a um total de 273.842 unidades e, em 2007, esse número registrava uma queda de $12,2 \%$, atingindo, portanto, a 240.527. Por sua vez, as duas faixas que mais perdem produtores são as unidades com até um e de um a dois hectares, que apresentam queda entre $43 \%$ e $47 \%$. Em termos de área total há, no 
período, um decréscimo de 0,2 , mas as menores faixas apresentam uma redução de $45 \%$. A trajetória de concentração confirma-se com um crescimento de $3 \%$ e $5 \%$ para as faixas de unidades de exploração, com área de 50 a 100 ha e mais que 100 ha. Na tabela 2, apresenta-se o segundo grande conjunto de culturas de "secano", que se referem aos cultivos industriais.

Tabela 2 - Cultivos Industriais (ha) - Espanha 2002-2010

\begin{tabular}{lrrrrr}
\hline & \multicolumn{5}{c}{ Período } \\
\cline { 2 - 6 } \multicolumn{1}{c}{ Culturas } & 2002 & 2004 & 2006 & 2008 & 2010 \\
\hline Girasol & 721.871 & 690.725 & 561.923 & 670.002 & 666.201 \\
Remolacha & & & & & \\
az. & 18.089 & 17.996 & 10.717 & 3.217 & 3.827 \\
Otros cult. & 15.427 & 6.368 & 4.610 & 4.758 & 24.032 \\
Colza & 4.216 & 2.568 & 5.539 & 10.259 & 12.306 \\
Algodon & 1.060 & 4.671 & 4.139 & 4.667 & 6.220 \\
\hline Totais & 762667 & 724332 & 588935 & 694912 & 714596
\end{tabular}

Fonte: Ministério da Agricultura Pesca e Alimentação (Espanha) 2010.

O terceiro grupo em importância de ocupação de área encontra-se vinculado à produção de forragens para manutenção da produção animal. Esse grupo é o que reúne maior importância relativa em áreas de "regadíos", atingindo $61 \%$ da área total de cultivo no país.

Em termos de participação no uso do solo, a área utilizada aproximase dos mesmos patamares das culturas industriais $(1,5 \%)$. Por sua vez, no que se refere à distribuição da atividade por faixa de tamanho das unidades de exploração, observa-se, no período, um crescimento das pequenas unidades e redução das grandes que se destinam às atividades mais intensivas de maior valor comercial, presentes no primeiro e no segundo grupos de cultivos.

As unidades de até vinte hectares reúnem um crescimento médio de participação, em número de unidades e área, de $23 \%$ e $18 \%$, respectivamente, enquanto que o grupo das explorações com mais de 100 ha apresentou uma redução de 5,1\% em unidades e de 8,5\% em área, o que responde pela redução total de área em torno de $1,6 \%$ para o período de 2003 a 2007. As atividades de produção de forrageiras são extremamente vinculadas aos processos de produção de pequenos animais, o que se consubstancia em uma alternativa de sobrevivência e manutenção das pequenas unidades de exploração campesina em Espanha (Tabela 3). 


\begin{tabular}{lrrrrr}
\hline \multirow{1}{*}{\multicolumn{1}{c}{ Culturas }} & 2002 & 2004 & 2006 & 2008 & 2010 \\
\cline { 2 - 6 } & 209.781 & 192.816 & 124.104 & 204.414 & 179.259 \\
Praderas polifitas & 68.279 & 59.859 & 61.057 & 66.714 & 89.705 \\
Alfalfa & 36.996 & 41.466 & 62.328 & 73.293 & 77.153 \\
Maiz forrajero & & & & & \\
Veza & 34.201 & 49.215 & 23.962 & 34.422 & 43.858 \\
(veza+avena) & 193.178 & 221.749 & 308.866 & 244.041 & 334.478 \\
Otros forrajes & 544.438 & 567.109 & 582.324 & 624.892 & 726.464
\end{tabular}

Fonte: Ministério da Agricultura Pesca e Alimentação (Espanha) 2010.

$\mathrm{O}$ último grupo destina-se à produção de leguminosas (Tabela 4). Flagrantemente vinculadas à produção alimentar, essas culturas não ocupam $1 \%$ da área total e apresentam oscilação nas áreas em decorrência de uma produção fortemente destinada a mercados locais e atividade de pequena unidade de produção.

A produção de leguminosas e seus declínios revelam claramente os processos de abandono das atividades agrícolas pelas pequenas unidades de produção. Os dados disponíveis demonstram uma queda de 43,3\% em termos de unidades de exploração que cultivaram as luminosas para grãos entre 2003 e 2007, sendo que as unidades de até 30 ha apresentaram uma redução superior a $50 \%$.

\begin{tabular}{lrrrrr}
\hline & \multicolumn{5}{c}{ Período } \\
\cline { 2 - 6 } Culturas & 2002 & 2004 & 2006 & 2008 & 2010 \\
\hline Veza & 124.136 & 103.788 & 36.240 & 22.001 & 88.072 \\
Yeros & 79.846 & 74.757 & 19.808 & 11.327 & 36.250 \\
Garbanzos & 56.765 & 60.739 & 25.131 & 24.884 & 21.366 \\
Guisantes & 43.105 & 91.371 & 114.527 & 69.916 & 145.623 \\
Habas & 26.265 & 35.623 & 21.212 & 11.383 & 18.770 \\
Lentejas & 25.449 & 35.105 & 22.386 & 19.207 & 21.997 \\
Otras leg. & 17.044 & 15.372 & 8.350 & 4.128 & 6.022 \\
\hline Totais & 374.612 & 418.760 & 249.660 & 164.855 & 340.110 \\
Fonte: Ministério da Agricultura Pesca e Alimentação & & & & &
\end{tabular}

Esses grupos de produção respondem por um sistema produtivo de plantas herbáceas anuais de "secano" e associam-se a esses cultivos a 
batata, as flores e as hortaliças, sendo estas mais representativas nos cultivos em "regadios". Integram-se ainda a esse grupo, os solos destinados ao "barbecho blanco y rastrojo". Tratam-se dos aproveitamentos mais extensos da península, mas que atualmente não ultrapassam a onze milhões de hectares e estão basicamente centrados em Castilla y Leon, Castilla y La Mancha, e em outras Comunidades Autônomas com áreas menos expressivas. Compõem o conjunto total de produção, entre outras, as depressões do Ebro (La Rioja, Navarra e Aragon) e Guadalquivir (de Andaluzia - Guadix e Baza - e Extremadura - Badajoz e Llerena, por exemplo), ainda que apresentem paisagens e características agroecológicas muito distintas das demais áreas de "secano".

Por sua vez, o contraste de produção tende a diminuir com os processos de especialização produtiva e redução das pequenas explorações que sempre foi, ao lado das condições geomorfológicas e climáticas, um fator de diferenciação nas paisagens espanholas.

No entanto, cabe considerar que esse sistema familiar passa por profundas transformações. A concentração das parcelas agrícolas, a mecanização, a intensificação de uso de fertilizantes e a utilização de sementes mais adaptadas foram as estratégias usadas para superar os sistemas de pousio, bem como a baixa resistência de alguns cultivares às precipitações escassas, à aridez do verão e aos prolongados frios de inverno, que impedem a rápida reconstituição da paisagem natural bem como a recuperação da fertilidade edáfica e a manutenção das unidades em sistemas tradicionais. Um processo que tem atuado fortemente sobre um espaço rural que perde suas raízes territoriais na mesma proporção em que perde seus sujeitos, práticas e formas de ocupação, ainda que mantenha alguns poucos sinais desse passado agrário.

Um passado que vai sendo substituído pela falsa ideia de mais produtivo e mais vivo. À medida que os ciclos produtivos se repetem ano a ano e os "barbechos blancos" reduzem-se, a cevada substitui o trigo com suas rotações mais curtas, com suas formas mais retas e de dimensões maiores, que conjuntamente reduzem os rebanhos de ovinos, reforçando a especialização produtiva e causando uma monotonia paisagística e, ao mesmo tempo, produtiva nas unidades de rurais.

No caso da cevada, ocorre uma situação muito precisa: trata-se de sua incorporação como matéria prima na produção de agrocombustíveis. 
Cabem ainda duas considerações importantes: a) as políticas fundiárias na Europa, no modelo de controle de produção e de eficiência produtivas, adotado dentro da PAC, procuram estabelecer sistemas e unidades com capacidade de escala na lógica de manter certa competitividade de produção e preços; b) a trajetória de envelhecimento da população rural tem produzido mecanismos de concentração produtiva, por meio de "sociedades agrárias" familiares, arrendamentos de terras e venda de direitos produtivos consolidados pela PAC (a concentração fundiária se estabelece de forma mais lenta e também velada na figura jurídica de "sociedades agrárias").

Não obstante, esses processos tendencialmente caminham na lógica de descaracterizar um modelo familiar de produção europeu, mas as ajudas econômicas e os ajustes que têm sido propostos e reformulados na política comum tendem a reforçar o paradigma da multifuncionalidade da agricultura $\mathrm{e}$, nesse caso, vinculam-se às estratégias de diversidade, recuperação ambiental paisagística e retenção da população no campo. Entretanto, temos aí, também, um paradoxo: se de um lado a multifuncionalidade é o discurso de proteção da agricultura europeia e de manutenção de subsídios, as unidades multifuncionais são as que menos recebem apoio financeiro, o que requer imediatamente uma reformulação das diretrizes e prioridades da política comum.

\section{Diversidade no rural espanhol}

Como salientado anteriormente, é paradoxal que, exatamente na perspectiva de multifuncionalidade da agricultura europeia, produzem-se resistências e manutenção de um padrão de diversidade produtiva no campo espanhol. A composição do uso do solo em Espanha permitiu a aplicação de um modelo de entropia, identificando o perfil de homogeneização territorial. O grau de entropia ou índice de diversidade produtiva foi apurado pelo modelo estabelecido por (Souza, 2008): 


$$
\begin{aligned}
& \mathrm{H}=\sum_{\mathrm{i}=1}^{\mathrm{n}}\left(\mathrm{y}_{\mathrm{i}} \cdot \ln \frac{1}{\mathrm{y}_{\mathrm{i}}}\right), \text { com } 0 \leq \mathrm{H} \leq \ln \mathrm{n}, \text { onde: } \\
& \mathrm{y}_{\mathrm{i}}=\frac{\mathrm{A}_{\mathrm{i}}}{\mathrm{A}}, \text { onde: } \\
& \mathrm{A}_{\mathrm{i}}=\text { área ocupada pela cultura i na área analisada; } \\
& \mathrm{A}=\text { área total analisada. }
\end{aligned}
$$

No caso de perfeita diversidade na distribuição de culturas (ou seja: $y_{i}=\frac{1}{n}$, i

n):

$$
\mathrm{H}=\ln \mathrm{n}
$$

No caso de perfeita dominação na distribuição de culturas (ou seja: quando u probabilidades yi é igual a 1 e as demais são nulas):

$$
\mathrm{H}=0 .
$$

Portanto, $0 \leq \mathrm{H} \leq \ln \mathrm{n}$, ou seja, a entropia é uma medida do grau de diversidade de uma distribuição de culturas em certa área

Neste sentido, o território espanhol revela ainda uma situação de diversidade e de permanência no campo que se coloca de forma extremamente oposta a algumas regiões de agricultura altamente especializada. Os gráficos abaixo demonstram a trajetória dos Índices de Diversidade Produtiva $(\mathrm{H})$ de Espanha e das principais Comunidades Autônomas. 


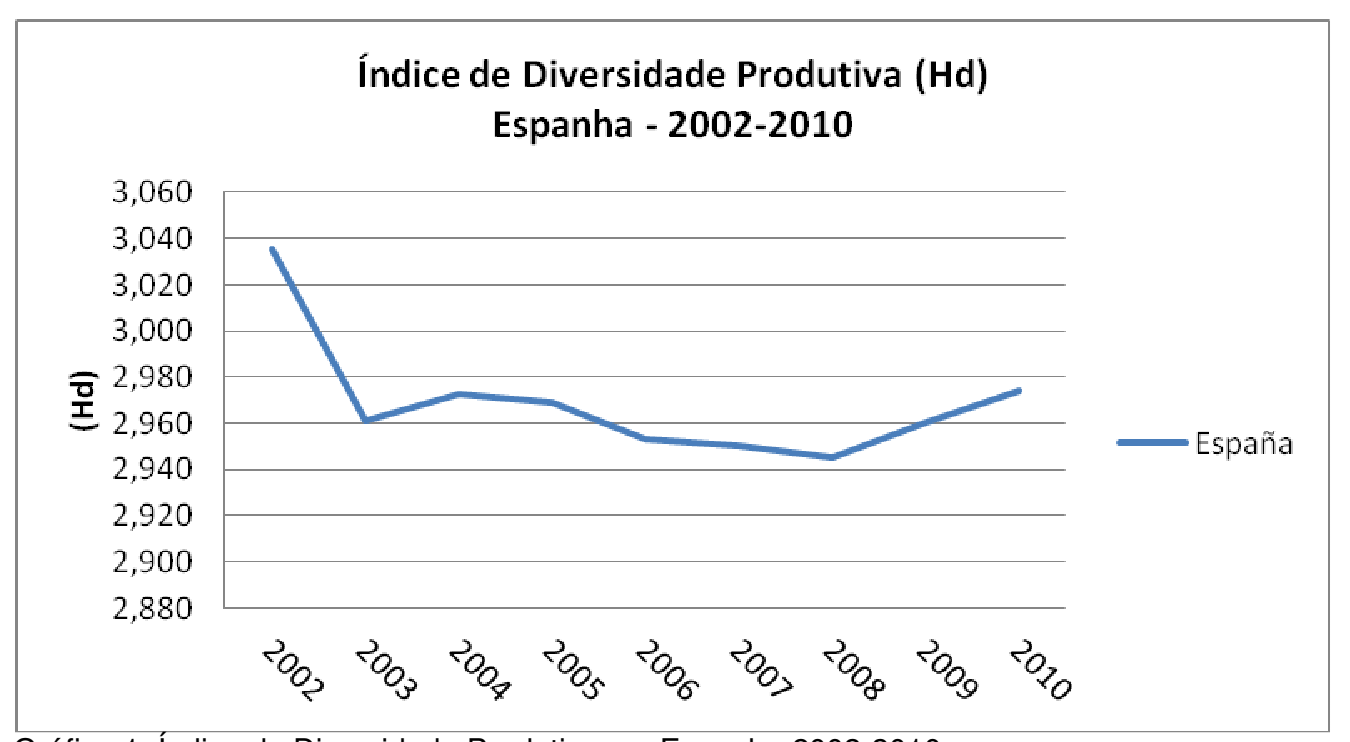

Gráfico 1. Índice de Diversidade Produtiva em Espanha 2002-2010

$\mathrm{O}$ índice médio espanhol apresentou sua trajetória de baixa diversidade nos períodos de 2003 a 2008, quando as novas práticas, determinadas pela Agenda 2000 (Marti, 1999), passaram a ser aplicadas gerando impactos produtivos. Esse período é também marcado pelo aumento do direcionamento da produção agrícola à transformação em etanol, quando as principais culturas, direcionadas à produção de agrocombustíveis, apresentam crescimento vertiginoso (tabela 1) diante de um processo que acompanhava a escala de preços internacionais do petróleo iniciados, a partir de 2003, com a ocupação do Iraque.

Nesse aspecto observa-se que a produção de cevada, trigo blando, aveia e girassol apresentaram trajetórias de crescimento, impactando fortemente a diversidade produtiva, uma vez que a primeira e última respondem pela atividade de produção de agrocombustível e apresentam as maiores taxas anuais de crescimento $(12 \% \mathrm{e} 13 \%)$.

No entanto, a alteração na lógica trajetória de recrudescimento a partir de 2008, com o período de crise e inflexão negativa nos preços internacionais do petróleo, revela a instabilidade e a insustentabilidade desses modelos produtivos. Um fenômeno que frente à resolução e distensão dos conflitos no Oriente Médio e às mudanças nos preços do petróleo, aliados à crise econômica européia, traduziram-se, 
posteriormente, em inflexão negativa, considerando a revisão dos programas de produção de agrocarburantes na Europa como um todo.

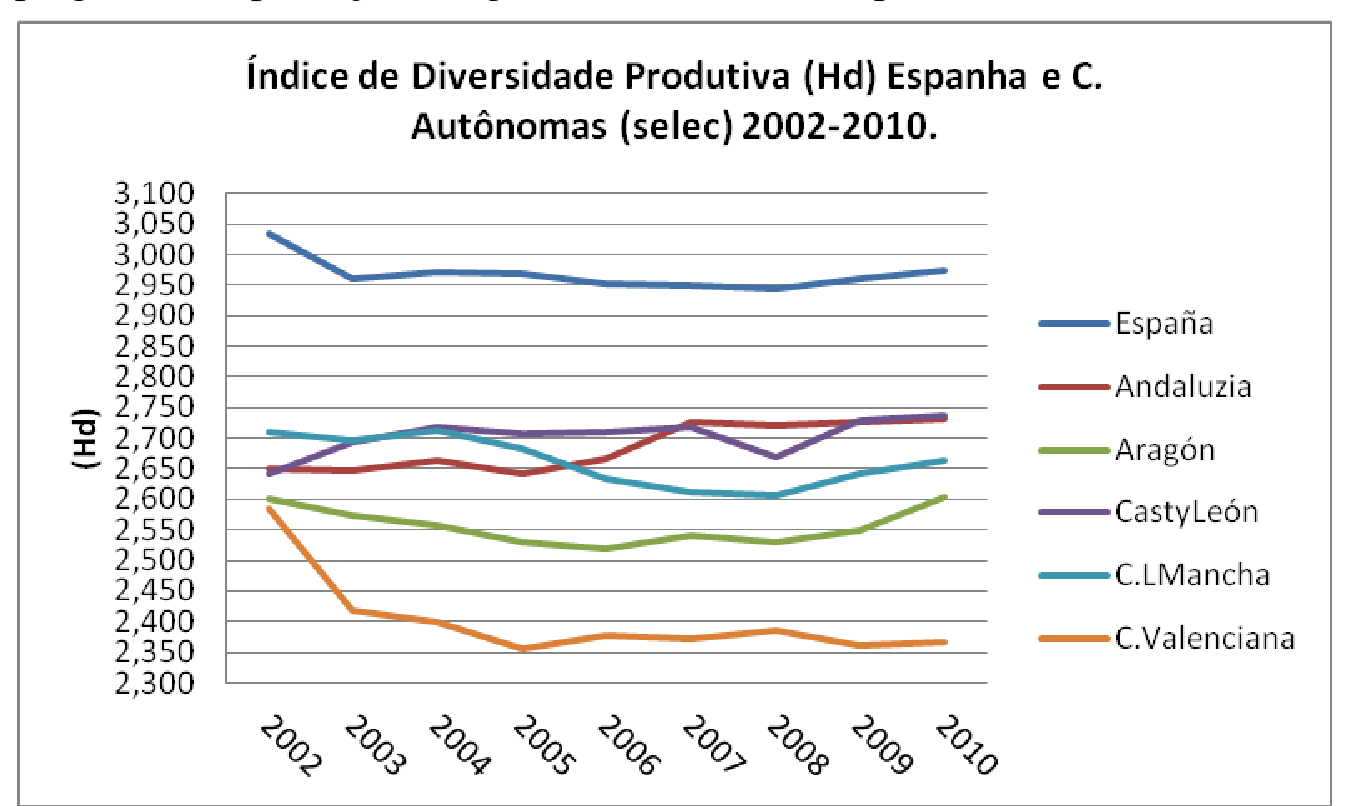

Gráfico 2 Índice de Diversidade Produtiva em Espanha e Comunidades Autonomas (selec) $2002-2010$.

Destaca-se, ainda, que o comportamento das curvas de diversidade das principais Comunidades Autônomas em muito aproximam-se da trajetória de Espanha, com duas flagrantes exceções: Andaluzia e Comunitat Valenciana. A primeira, por conta de concentrar em suas terras grande parte da produção de oliveiras e a produção de girassol de forma mais competitiva que outras áreas de produção no país, determinando uma lógica de especialização regional produtiva.

O fato de a produção de girassol apresentar maior capacidade de utilização na geração de agrocarburantes mantém certa demanda por essa, decorrente do parque produtivo instalado no país. Por outro lado, as reduções das áreas das culturas (cevada e trigo) não alteram a disposição da diversidade, em função de o modelo estatístico ponderar a distribuição mais equitativa da área, reduzindo o efeito de homogeneização territorial quando este nível da distribuição de área estabelece-se. 
No caso da Comunitat de Valencia, a trajetória de redução da biodiversidade estabelece-se pelo aumento de "matorrales", considerando que essa região passa por um profundo processo de abandono das terras agrícolas dada a sua baixa fertilidade, escassez de água e agudo processo de desertificação, observável no mapa (Figura1) de aridez da Espanha (España, 2008).

Essa diversidade produtiva é identificada pelo uso e ocupação da terra como ação concreta de apropriação da natureza, como representação objetiva das formas capitalistas de subsunção do trabalho e da natureza, na consolidação territorial das relações sociais de produção e nas resistências campesinas a esses processos. Poder e hegemonia que consolidam territórios e que, sobre determinadas circunstâncias, revelam homogeneidades e/ou singularidades nos modos de fazer.

Essas concretudes específicas são constitutivas das formas de reprodução social, sínteses da lógica de valor (material e imaterial) dos capitalistas e dos camponeses em relação à terra e ao trabalho, concepções práticas de mundo dos sujeitos. Valor de Uso e Troca internalizados, materializados na consciência (como dimensão prática) que determinam a posição da terra no mercado e/ou na produção, configurando formas e diferenciações territoriais. (Souza, 2009).

A determinação do padrão de uso e ocupação do solo apresenta importância significativa, na medida em que pode-se inferir as dinâmicas de crescimento econômico e de territorialização das forças produtivas hegemônicas, em detrimento de uma visão de desenvolvimento que permita conviver com outras territorialidades, outras formas de projeção humana sobre o espaço, no caso, as campesinas.

As análises das comunidades autônomas espanholas revelam que as políticas territoriais da PAC determinam uma forma de ocupação extremamente diversificada, de reduzida homogeneização da paisagem, em que o índice de diversidade $(\mathrm{H})$ é superior a 2,55: determinadas Comunidades Autônomas apresentaram índices superiores a 3,0 (H). Como exemplo, destaca-se, pela reduzida área, a Comunidade de La Rioja que, em 2002, apresentava um índice de 2,66 e, em 2010, atingiu 3,07 (H).

Embora as condições de reprodução social no campo espanhol sejam difíceis, observa-se que se mantém um padrão de diversidade extremamente elevado. 
Figura 1 -Mapa de Aridez de Espanha

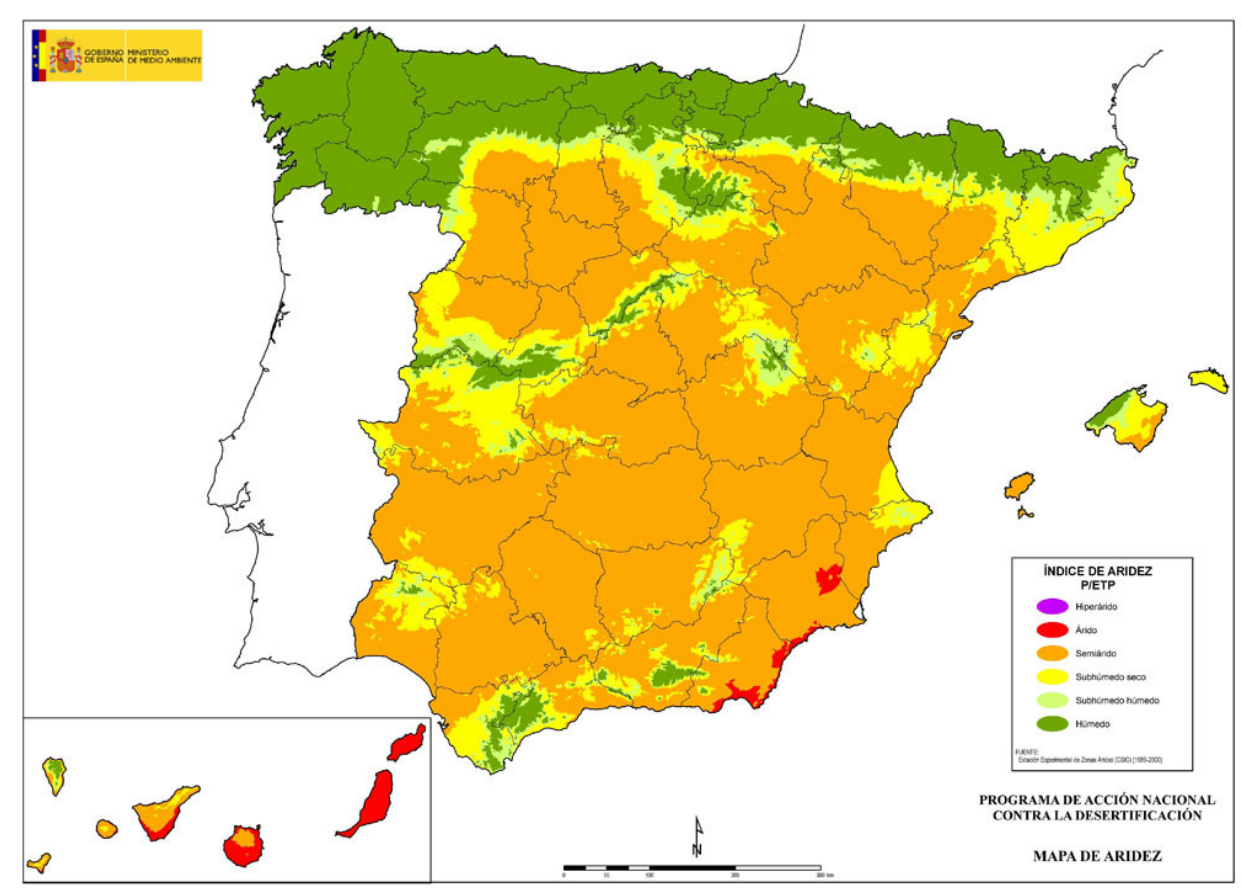

Fonte: Ministerio de Médio

http://www.magrama.gob.es/es/biodiversidad/temas/lucha-contra-la-

desertificacion/1 Aridez red1 tcm7-25878.jpg

Ambiente y Medio Rural y Marino

A diferenciação desse processo estabelece-se, unicamente, em relação às Ilhas Canárias, com índice médio, no período, de 1,66, mas 
considerando a reduzida área agrícola do território, esse índice ainda não representa uma condição de homogeneização ${ }^{3}$.

Outro aspecto a ser considerado na diversidade produtiva é o número de culturas que estão diretamente vinculadas à segurança alimentar e aos sistemas de consumo regional, identificando menor padronização de consumo.

Neste contexto, em que se observa a perda de diversidade agrícola e alimentar da autossuficiência, a resposta dos camponeses foi presidida por algumas associações agrícolas e grupos de ação local que defendem a variedade de sistemas de uso e riqueza de recursos naturais da Península Ibérica. Junto com a presença histórica das grandes paisagens agrícolas da trilogia mediterrânea (cereais, vinhas e olivais, vinho, pão e óleo), defendem a preservação de áreas e "nichos ecológicos" que mantêm a biodiversidade agrícola e grande patrimônio a nível regional ou local, ou a proteção de ecossistemas agroflorestais, extensiva a identidades paisagísticas, como os prados, o que representa alta estabilidade e renovação das energias naturais através do uso inteligente da floresta mediterrânica pela atividade humana.

As respostas configuram-se como as mais ativas nos últimos anos, em grande parte condicionadas pela CSF, e têm presidido o Programa de Desenvolvimento Rural, gerenciado por Grupos de Ação Local no âmbito da abordagem LEADER. O compromisso com a diversificação das zonas rurais seria, assim, adicionado aos agricultores e às organizações agrícolas que estão comprometidos com a agricultura biológica, diferindo-se da substituição das práticas tradicionais exclusivamente industrializadas, de uma agricultura absolutamente mercantilizada.

${ }^{3}$ Em termos comparativos destaca-se que Souza (2008) identificou que os índices de diversidade produtiva no estado de São Paulo atingem padrões médios de 1,63 H. Em regiões tradicionais e/ou de expansão do setor sucroenergético, os índices oscilam entre $1,4 \mathrm{H}$ e $1,7 \mathrm{H}$, respectivamente, caracterizando um processo de homogeneização do território e da paisagem rural paulista. Em regiões com predominância de agricultura familiar (Jales, por exemplo) este índice aproxima-se dos identificados em Espanha, $2,45 \mathrm{H}$. 


\section{Conclusões}

O monopólio econômico de determinado setor determina a homogeneização do território. $\mathrm{O}$ modelo identifica o perfil de homogeneização territorial considerando que quanto o menor o índice $(\mathrm{H})$, maior o domínio territorial de determinada atividade, maior a homogeneização e a redução da diversidade sócio-produtiva. Esse processo é resultado do caráter concentrador e excludente que a lógica de liberalização econômica produz.

A restrição de políticas de desenvolvimento territorial, pautadas na preservação ambiental e na fixação dos agricultores campesinos, pode acelerar processos de concentração da terra e abandono à agricultura, com significativa redução de sua diversidade ambiental, social e cultural.

Os elementos comparativos aqui utilizados permitem inferir os riscos do discurso que propõe o fim das políticas públicas no campo europeu como determinante no processo de concentração e homogeneização. Isso é observado não apenas no velho continente, mas, sobretudo, na posição de subalternidade que a produção primária impõe na geopolítica mundial aos "países agrícolas" e os perniciosos efeitos sobre a diversidade produtiva ambiental e sobre a reprodução social do campesinato no mundo.

Assim, observamos uma luta fundamental que trata da "desglobalização" da produção alimentar, que representa a permanência de sistemas, modos e tipos de produção como mecanismo de deter a commoditização, que se revela em processo de subsunção da natureza e do trabalho.

POR UMA DESGLOBALIZAÇÃO DA PRODUÇÃO ALIMENTAR COMMODITIZAÇÃO DA AGRICULTURA E DIVERSIDADE PRODUTIVA: UMA ANÁLISE DE ESPANHA

Resumo: O presente artigo apresenta uma reflexão sobre os ainda positivos efeitos da Política Agrícola Comum Europeia (PAC-UE) relativa à sua diversidade produtiva. A análise realiza-se sobre as formas de uso e ocupação do solo, no período de 2002 a 2010, nas 17 Comunidades Autônomas de Espanha, e identifica os processos de especialização regional produtiva, concentração da terra e redução das pequenas unidades de produção. Essa dinâmica indica, ainda, um processo de commoditização 
da agricultura e, por sua vez, a redução da diversidade produtiva. Esses fatores revelam a necessidade de "des-globalizar" a produção e o consumo de alimentos como estratégia de preservação ambiental e sócio-produtiva, de manutenção da produção regional e banco genético de alimentos, considerando a commoditização como lógica de subsunção do trabalho e a mercantilização da natureza.

Palavras-chave: política agrícola, especialização produtiva, homogeneização da paisagem, Espanha.

FOR A DE-GLOBALIZATION OF FOOD PRODUCTION AGRICULTURE COMMODITIZATION DIVERSITY : AN ANALYSIS OF SPAIN

Abstract: This article presents a reflection on the still positive effects of European Common Agricultural Policy (ACP-EU) on the productive diversity. The analysis is carried out on ways to use and land cover in the period 2002 to 2010, the 17 Autonomous Communities of Spain and identifying the processes of regional specialization of production, land concentration and reduction of small production units. This also indicates a dynamic process of commoditization of agriculture and the reduction of productive diversity. These factors reveal the need for "non-globalizing" the production and consumption of food as a strategy for environmental conservation and socio-productive, maintenance of regional production and gene bank for food, considering the commoditization as logical subsumption of labor and the mercantilization of nature.

Keywords: agricultural policy, productive specialization, landscapes homogenization, Spain.

\section{BIBLIOGRAFIA}

CABERO DIEGUES, V. (2008) Las montañas olvidadas, las montañas conquistadas, las montañas preservadas. ¿Del abandono y desplobación al desarrollo sostenible? JACINTO, R, BENTO, V. (Coords) $O$ interior raiano do centro de Portugal. Outras fronteiras, novos intercâmbios. Porto: Campo das Letras. Iberografias n ${ }^{\circ} .8$, pp. 405-425.

CABERO DIEGUES, V, TREJO JIMÉNES, M.C., FERNÁNDEZ FERNÁNDEZ, V. (2010) Pobreza y exclusión social en el ámbito rural. Cuaderno Europeo, 8:29-44. 
DI PIETRO, F., BALENT, G. (1997) Dynamique des pratiques pastorale et des paysages: une approche pluri-écchelle appliquées aux Pyrénées ariégoises. Agronomie, 17:139-155.

ESPAÑA - Ministerio de Medio Ambiente y Medio Rural y Marino. PAND - Programa de Acción Nacional contra la Desertificación. (2008) Madrid: PAND.

ESPARCIA PÉRES, J, NOGUERA TUR, J., PITARCH GARRIFO, M.D. LEADER en España : desarrollo rural, poder, legitimación, aprendizaje y nuevas estructuras. Doc. Anál.Geogr. 2000, 37:95-113.

MARTI, A.M. La PAC entre la Agenda 2000 y la ronda del milenio. Agricultura. 1999, 810:1082-1088.

MATA OLMO, R. "Los paisages Agrários" in GIL OLCINA, A., GÓMES MENDOZA, J. (Coord). (2009) Geografia de España. Barcelona. Ariel. pp.299-340.

NUNES, A. (2008) Abandono do espaço agrícola na "Beira Trasmontana". Porto: Campo das Letras.

SOUZA, J.G. (2008) Questão de Método: a homogeneização do território rural paulista. Jaboticabal: FCT-Unesp. (Tese de Livre Docência).

SOUZA, J. G. (2009) Limites do Território. Agrária, São Paulo, 10/11, pp. 99-130.

SOUZA, J. G. A (2010) Geografia agrária e seus elementos de crítica sobre o avanço do capital monopolista no campo brasileiro. Canadian Journal of Latin American and Caribbean Studies. 34:147-176. 